\title{
Correlation analysis of field-aligned currents from the magnetic measurements of GRACE follow-on mission
}

\author{
Chao Xiong ${ }^{1 *} \mathbb{0}$, Claudia Stolle ${ }^{2}$, Ingo Michaelis ${ }^{3}$, Hermann Lühr ${ }^{3}$, Yunliang Zhou' ${ }^{1}$, Hui Wang ${ }^{1}$,
} Guram Kervalishvili ${ }^{3}$ and Jan Rauberg ${ }^{3}$

\begin{abstract}
In this study we performed a detailed analysis on the scale-size of field-aligned currents (FACs) at auroral latitudes, using the well-calibrated magnetic data from the non-dedicated magnetic field mission, Gravity Recovery and Climate Experiment Follow-On (GRACE-FO). With two spacecraft following each other, the GRACE-FO provides a good opportunity to identify the variation of FACs with different scale lengths. The results show that the auroral FACs can be classified into two groups: the small-scale ones, shorter than some tens of kilometers, dominated by kinetic Alfvén waves, are quite dynamic; and the large-scale ones, typically larger than $150 \mathrm{~km}$, can be considered as quasi-static and persist longer than $1 \mathrm{~min}$. The GRACE-FO observations also reveal that the small-scale FACs at the same location sometimes can persist over 25 s, e.g., around dusk and dawn hours, which is longer than the typical persistent period (10 s) of kinetic Alfvén waves as earlier reported. The FAC structures show clear magnetic local time dependence, with higher correlations between the spacecraft around dusk and dawn hours; lower correlations are found around midnight and lowest correlations around noon, implying that the small-scale FACs most frequently appear at the noon cusp region. Slightly better correlations of FACs between two spacecraft are found during local summer, and such seasonal dependence is dominated by the correlations of small-scale FACs at noon. However, further analysis shows that the small-scale FACs at noon have largest occurrence and intensity during local summer, which reveals that when interpreting the cross-correlation analysis the intensity of FACs needs to be taken into account.
\end{abstract}

\footnotetext{
*Correspondence: xiongchao@whu.edu.cn

${ }^{1}$ Department of Space Physics, Electronic Information School, Wuhan

University, Wuhan 430072, China

Full list of author information is available at the end of the article
}

\section{Springer Open}

(c) The Author(s) 2021. Open Access This article is licensed under a Creative Commons Attribution 4.0 International License, which permits use, sharing, adaptation, distribution and reproduction in any medium or format, as long as you give appropriate credit to the original author(s) and the source, provide a link to the Creative Commons licence, and indicate if changes were made. The images or other third party material in this article are included in the article's Creative Commons licence, unless indicated otherwise in a credit line to the material. If material is not included in the article's Creative Commons licence and your intended use is not permitted by statutory regulation or exceeds the permitted use, you will need to obtain permission directly from the copyright holder. To view a copy of this licence, visit http://creativecommons.org/licenses/by/4.0/. 


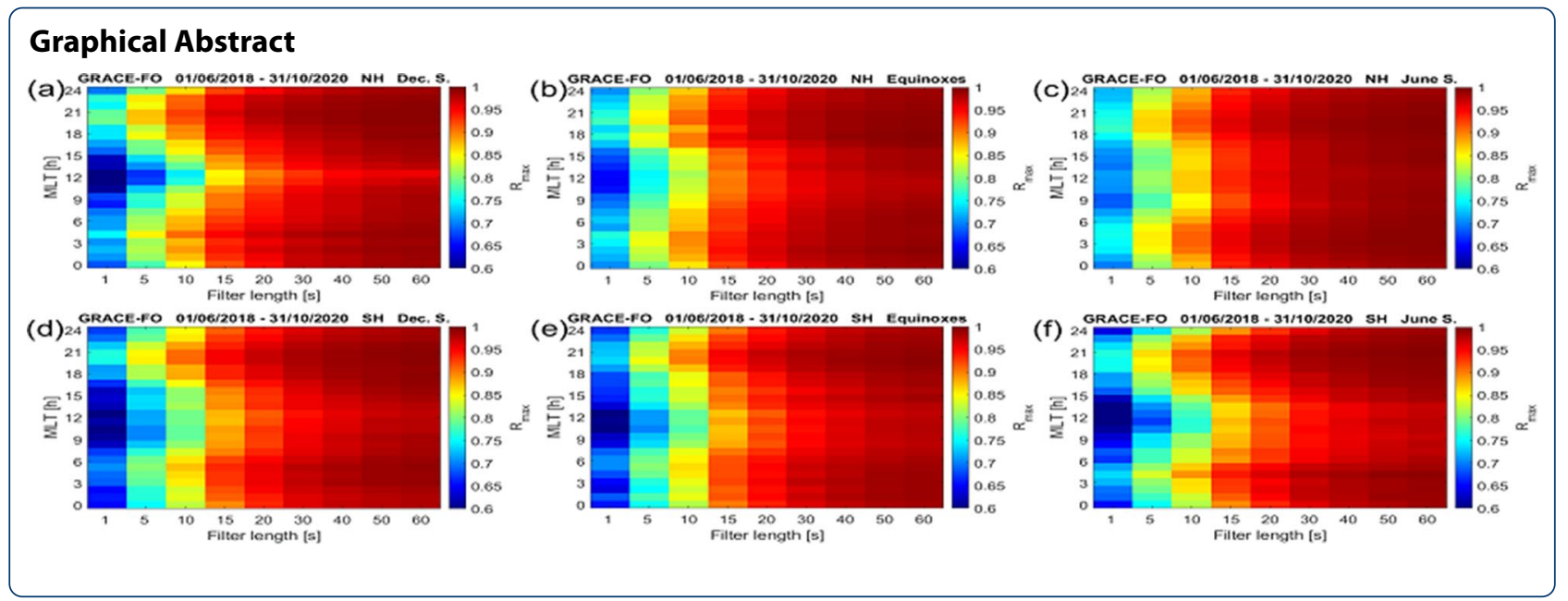

\section{Introduction}

Auroral field-aligned currents (FACs) are one of the main energy transfer mechanisms between the magnetosphere and ionosphere. The concept of auroral FACs was first proposed by the Norwegian scientist Kristian Birkeland in the early twentieth century (Birkeland 1908, 1913), but only 60 years later the existence of such currents was first confirmed from magnetic measurements of the 1963 38C satellite (Zmuda 1966). Persistent perturbations along the perpendicular direction of the magnetic field at auroral latitudes were observed, and such magnetic perturbations are believed to be caused by the auroral FACs. Later, with several-year of magnetic measurements from the TRIAD satellite, Iijima and Potemra (1976a, b) revealed the typical magnetic local time (MLT) and magnetic latitude (MLAT) distribution of FACs, that exhibited as a pair of current sheets with opposite polarity (upward/downward). The poleward and equatorward FAC sheets are called region $1(\mathrm{R} 1)$ and region 2 (R2) currents, respectively.

Based on accumulated magnetic measurements from later Earth's magnetic field missions, such as MagSat (e.g., Mobley et al. 1980), Freja (e.g., Lühr et al. 1996), CHAllenging Minisatellite Payload (CHAMP, e.g., Wang et al. 2005), and the recent Swarm (e.g., Ritter et al. 2013), the origin, distribution characteristics and responses to the solar wind/interplanetary magnetic field (IMF) changes of FACs have been widely investigated (see also Milan et al. 2010, 2017; Shi et al. 2010; Ganushkina et al. 2015; Trenchi et al. 2019). The generation of R1 currents are believed to be related to the processes in the outer magnetosphere, while the processes in the inner magnetosphere are considered to dominate the generation and variation of R2 currents. From a global view, the R1/R2 FACs flow into/out of the ionosphere on the dawn side, and vice versa on the dusk side. The polarity and the MLT versus MLAT distribution of FACs are closely controlled by the strength and orientation of IMF (e.g., Anderson et al. 2008). Under southward IMF condition, the R1/R2 currents appear much clearer as one pair, while under northward IMF condition, the R1 FACs are sometimes accompanied at the poleward side by an additional pair of currents referred as the NBZ (Northward IMF BZ) currents, flowing mainly near the dayside cusp region (e.g., Iijima et al. 1984). Further asymmetric features are also found in the distribution of FACs. For example, the FACs intensity is on average larger in local summer than in other seasons, and also larger in the northern hemisphere than that in the southern hemisphere (Cnossen et al. 2012; Workayehu et al. 2020). In addition, the average strength of R1 FACs is larger than the average strength of R2 FACs (e.g., Benkevich et al. 2000; Zhou and Lühr 2017; Laundal et al. 2017; Shi et al. 2019).

However, from rocket (e.g., Primdahl et al. 1984) and satellite single orbit probes (e.g., Lühr et al. 1994), the FACs do not simply appear as a pair of R1/R2 current sheets but contain a wide range of scales from largescale Birkeland currents of thousand kilometers, to scales down to a few hundred meters. The averaged large-scale R1/R2 FACs are found with a typical intensity less than $1 \mu \mathrm{A} / \mathrm{m}^{2}$, while the small-scale currents sometimes show instantaneous density peaks reaching several hundred $\mu \mathrm{A} / \mathrm{m}^{2}$. These small and rapidly changing FAC structures are filamentary rather than sheet-like. Since the intensity of small-scale FACs is significantly larger than those from large-scale FACs, it also means that the smaller scale FACs are an important candidate for transporting energy, e.g., the heating of local ionosphere and thermosphere (Lühr et al. 2004). Thus, understanding the general behavior of small-scale FACs is important for improving the current knowledge of the magnetosphere-ionosphere coupling processes. 
To separate different scales of FACs from single satellite measurements, filters with different cutoff frequencies are commonly used. Ishii et al. (1992) applied such filters to the observations of DE-2 satellite, and they found that for small-scale structures of FACs $(<32 \mathrm{~km})$ the ratio between east-west magnetic field component and north-south electric field component is close to the Alfvén wave velocity, while for the larger scale structures of FACs $(>64 \mathrm{~km})$ the ratio between east-west magnetic field component and north-south electric field component is close to the value of height-integrated ionospheric Pederson conductivity. They further suggested that smallscale FACs are dominated by the Alfvén wave, and largescale FACs can be considered as quasi-static. Focusing on the small-scale FACs with intensity above tens of $\mu \mathrm{A} / \mathrm{m}^{2}$, Neubert and Christiansen (2003) as well as Rother et al. (2007) performed comprehensive investigations of FACs at sub-kilometer size, based on high-resolution magnetic measurements from the Ørsted and Challenging Minisatellite Payload (CHAMP) satellites, respectively. One issue related to the small-scale FACs derived from single satellite is that the temporal and spatial variations cannot effectively be separated. Only recently it has become possible to solve this problem using simultaneous measurements from multi-satellite constellation. Gjerloev et al. (2011) analyzed the magnetic field signatures from a flying string-of-pearls constellation, ST5, which flew with inter-satellite separation gradually increasing from a few seconds to a few minutes. They found that small-scale FACs show significant variability over the time of intersatellite separation, while large-scale FACs are stable and can last for several minutes. Based on observations from the Swarm constellation, Lühr et al. (2014) found a typical persistent period of the order of $10 \mathrm{~s}$ for small-scale FACs, while large-scale FACs can be regarded stationary for more than $60 \mathrm{~s}$. They also found that for smallscale FACs, the longitudinal extension is on average four times the latitudinal width on the night side, while on the dayside the latitudinal and longitudinal scales are comparable.

The ST5 satellites were in a sun-synchronous orbits, which covered the morning and evening hours, and Gjerloev et al. (2011) used only 3 months of data in their study. Though the MLT of Swarm gradually changes over time, Lühr et al. (2014) used only one and a half months of data at the beginning of the mission. At that time, the three Swarm satellites flew around noon/midnight hours. Therefore, a picture of the full magnetic local time (MLT) dependence of small-scale FAC structures is still pending. In this study, we use more than 2 years of magnetic data from the Gravity Recovery and Climate Experiment Follow-On (GRACE-FO) mission that recovered all MLT. Different to the ST5 and Swarm constellations, the
GRACE-FO mission compromise two identical spacecraft, named GF1 and GF2 in the following, and they fly at the same orbit with GF1 leading GF2 by a distance of approximately $200 \mathrm{~km}$. Such a stable configuration is especially suitable to reflect the variation of FACs with scale length smaller or comparable to the separation of two spacecraft.

\section{Data and method \\ GRACE-FO mission and the magnetic measurements}

The GRACE-FO mission is a successor to the previous GRACE mission, and the primary objective of both missions is to obtain precise, global, and high-resolution models for the static and the time variable components of Earth's gravity field (Tapley et al. 2004; Landerer et al. 2020). For this purpose, precise measurements of the satellite separation range and range rate are performed. Special attention is paid that the two spacecraft follow each other on the same orbit, and differences in longitude vary less than $0.2^{\circ}$. As part of the attitude and orbit control system, the GRACE-FO mission carries magnetometers that aim to enhance the satellite's navigation. Stolle et al. (2021) performed detailed calibration of the magnetic measurements from GRACE-FO. They showed that during times of geomagnetically quiet conditions, the mean magnetic residual to the geomagnetic model CHAOS-7 (Finlay et al. 2020) is around $1 \mathrm{nT}$ with standard deviations below $10 \mathrm{nT}$, which is remarkably good for a nonscience instrument. They also showed that the derived auroral FACs compare well in amplitude and statistical behavior with earlier results from other missions. It confirms that after an appropriate calibration and characterization of artificial magnetic disturbances, the magnetic observations of GRACE-FO are valuable assets to investigate the natural variability of Earth's magnetic field. Details about the calibration and initial validation of GRACE-FO magnetic data are given in Stolle et al. (2021).

\section{FACs derived from magnetic measurements of GRACE-FO}

For calculating FACs, we follow the approach described by Lühr et al. (2014) and Xiong et al. (2020). The calibrated magnetic field vectors from GRACE-FO are first converted into the geographic north-east-center (NEC) reference frame, then contributions from the Earth's core, crust, and magnetosphere are removed using predictions from the CHAOS-7 model (Finlay et al. 2020). By this procedure, the magnetic contribution originating from the ionospheric currents is extracted.

According to Ampère's law, the vertical current component $j_{z}$ is derived from magnetic signatures: 


$$
j_{z}=\frac{1}{\mu_{0}}\left(\frac{\mathrm{d} b_{y}}{\mathrm{~d} x}-\frac{\mathrm{d} b_{x}}{\mathrm{~d} y}\right)
$$

where $b_{x}$ and $b_{y}$ are the northward and eastward components of magnetic residuals, respectively, and $\mu_{0}$ is the permeability of free space. By assuming the vertical current sheets are elongated infinitely in the zonal direction, the second term of the right-hand side of Eq. (1), $\frac{\mathrm{d} b_{x}}{\mathrm{~d} y}$, is negligible. The radial currents are derived and then transferred to FACs by projection into the direction of the local magnetic field line:

$$
j_{\|}=-\frac{j_{z}}{\sin I}
$$

where $I$ is the inclination of the local magnetic field line. As the magnetic field points approximately in vertical direction at auroral latitudes, the density of FACs is nearly the same as the intensity of vertical currents.

\section{Results}

Figure 1 shows the altitude, local time (LT) coverage and time lag between GF1 (black) and GF2 (red) when they fly over the geographic equator. The altitude of the two spacecraft is about $490 \sim 520 \mathrm{~km}$, with GF2 following directly behind GF1. The thicker and thinner lines represent the ascending and descending orbits, respectively. The LT coverage of both GF1 and GF2 orbits slowly progresses, and considering both the ascending and descending orbits it needs about 161 days to cover the 24 local time hours, which is comparable with the LT precession of the GRACE mission (e.g., Xiong et al. 2010). During the period from 1 June 2018 to 31 October 2020, the time lag between GF1 and GF2 varies between 22 and $29 \mathrm{~s}$. Assuming a velocity of $7.5 \mathrm{~km} / \mathrm{s}$

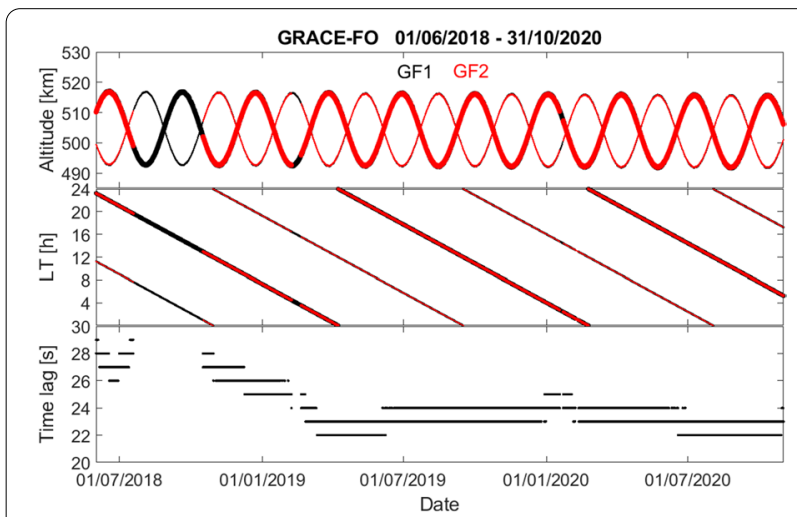

Fig. 1 The (top) altitude, (middle) LT coverage and (bottom) time lag between GF1 (black) and GF2 (red) when they fly over the geographic equator. The thicker and thinner lines represent the ascending and descending orbits, respectively. GF2 is plotted over GF1. The line is, therefore, black if GF2 data were not available for GRACE-FO, such a time lag corresponds to a distance of $165-220 \mathrm{~km}$ between GF1 and GF2.

The top panel of Fig. 2 shows the time series of FACs derived from GF1 (black) and GF2 (red) for an event on 31 October 2019 when they crossed the southern auroral latitudes. The upper panel shows that the FACs derived from the two GRACE-FO satellites have very similar variations along their orbits, but with a time delay of about $24 \mathrm{~s}$. The middle panel shows the original $1-\mathrm{Hz}$ FAC densities plotted over MLAT. Here MLAT refers to the Apex latitude calculated by the model of Emmert et al. (2010). In this example the FAC signatures compare well to each other both in latitude and amplitude, with enhanced FAC activity observed between $-64^{\circ}$ and $-83^{\circ}$ as well as $-68^{\circ}$ and $-84^{\circ}$ MLAT on the dusk and dawn sides, respectively. Outside the auroral latitudes, the FACs from both satellites show amplitudes less than $0.5 \mu \mathrm{A} / \mathrm{m}^{2}$. This can be regarded as the noise floor. The bottom panel shows the large-scale FACs structures, calculated by applying a low-pass filter with cutoff period of $20 \mathrm{~s}$ (corresponding to about $150 \mathrm{~km}$ along orbit). Comparing the middle and lower panel, it shows that remaining differences in peak amplitude between GF1 and GF2 FACs are larger for small-scale structures (less than $150 \mathrm{~km}$, middle

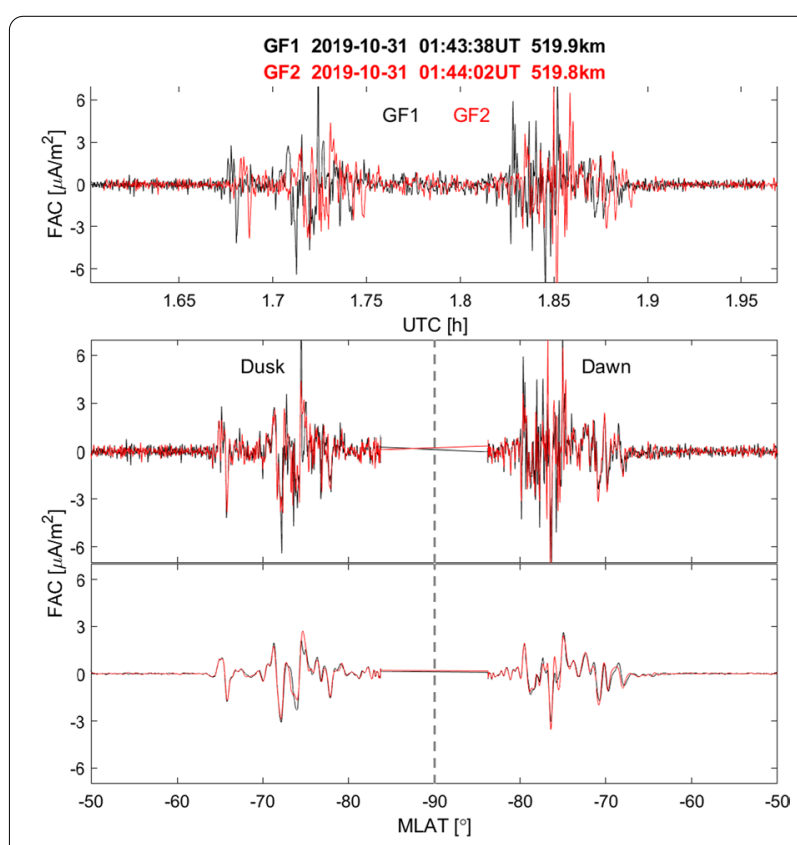

Fig. 2 Profile of FACs derived from GF1 (black) and GF2 (red) for an event on 31 October 2019 when the mission crossed the southern auroral latitudes. The upper panel shows the time series, while the lower two panels show the variations over MLAT, of (middle) the original $1-\mathrm{Hz}$ resolution and (bottom) low-pass filtered (cutoff period of 20 s) data 
panel), but the peaks of large-scale structures (lower panel) follow each other well.

To get a more quantitative picture of the temporal variability of small-scale FACs, we performed crosscorrelation analyses of the FACs time series for each high-latitude orbital crossing $\left(|\mathrm{MLAT}|>50^{\circ}\right)$ from two spacecraft. The derived maximum correlation coefficients $\left(R_{\max }\right)$ are recorded for further statistics. Note that lower $R_{\max }$ means the FACs contain dynamic small-scale structures with scale lengths shorter than the distance of the two spacecraft. However, sometimes the GF1 and GF2 satellites did not observe clear FAC currents at high latitudes. Possible reasons could be that either the GRACE-FO satellites did not reach the auroral latitudes, or the FAC signatures are so weak that the GRACE-FO onboard magnetometers are not sensitive enough to reflect the weak currents. Two such examples are shown in Fig. 3a, b. In these two events, the $R_{\max }$ between GF1 and GF2 are quite low (less than 0.2 ), but it does not mean that the small-scale FAC structures are dynamic, as argued above. Therefore, we excluded such events from the statistical analysis.

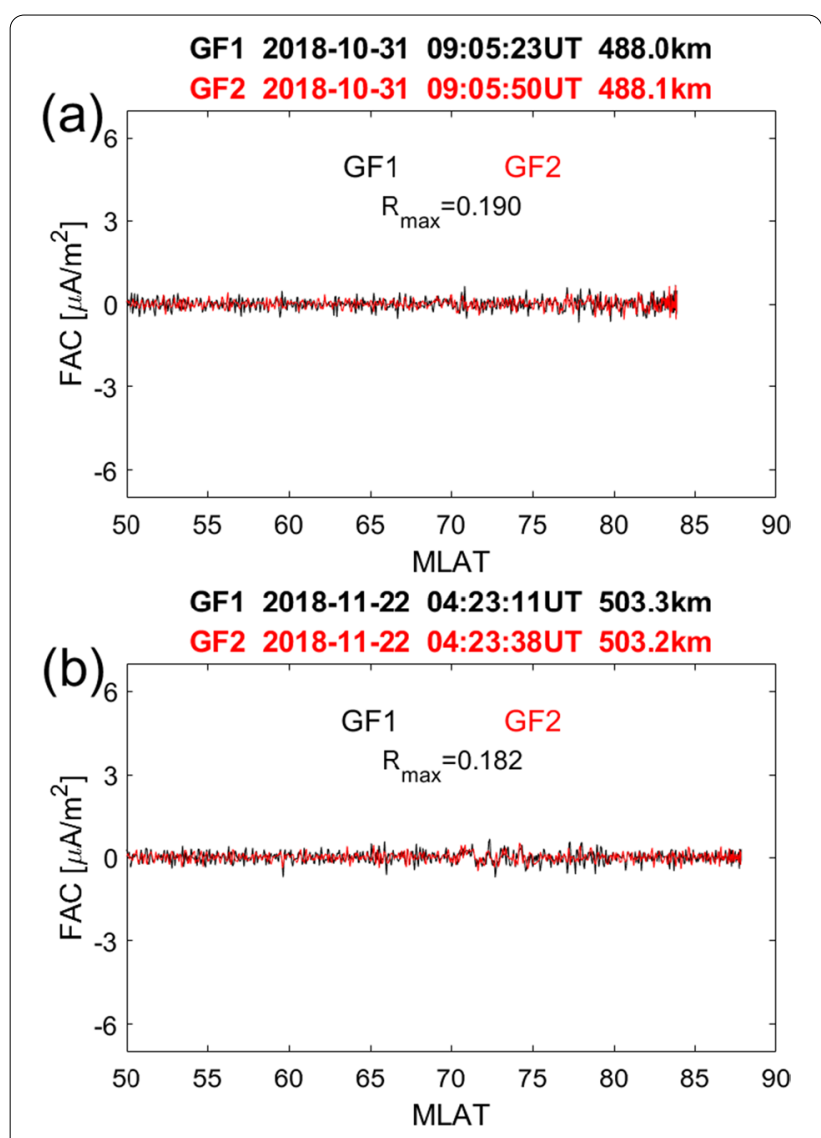

Fig. 3 Two examples of FACs with very low current intensity
To identify events with no or very weak FAC signatures, the maxima of the absolute FAC intensity from GF1 and GF2 are identified for each high-latitude orbital crossing, and then their mean value, $\overline{|F A C|}$, is recorded. Figure 4 shows the distribution of $R_{\max }$ over $\overline{|F A C|}$ for the two hemispheres. We find the majority of $R_{\max }$ being low $(<0.5)$ for low amplitude of $\overline{|\mathrm{FAC}|}$, e.g., $1 \mu \mathrm{A} / \mathrm{m}^{2}$. Therefore, these events are disregarded from the statistics. The excluded events correspond to 3.9 and $16.1 \%$ of the total number of events in the northern and southern hemispheres, respectively.

Figure 5 presents the seasonal distribution of $R_{\max }$ as expressed by the day of year (DOY) in the two hemispheres. $R_{\max }$ derived from each high-latitude orbital crossing is presented as grey dots, and the median values in each DOY bin (width of 1 day) are shown as blue circles, that vary between 0.6 and 0.7 . In the northern hemisphere the median values of $R_{\max }$ are slightly larger during June solstice months, while an opposite dependence is found in the southern hemisphere, though not as prominent as that in the northern hemisphere. In

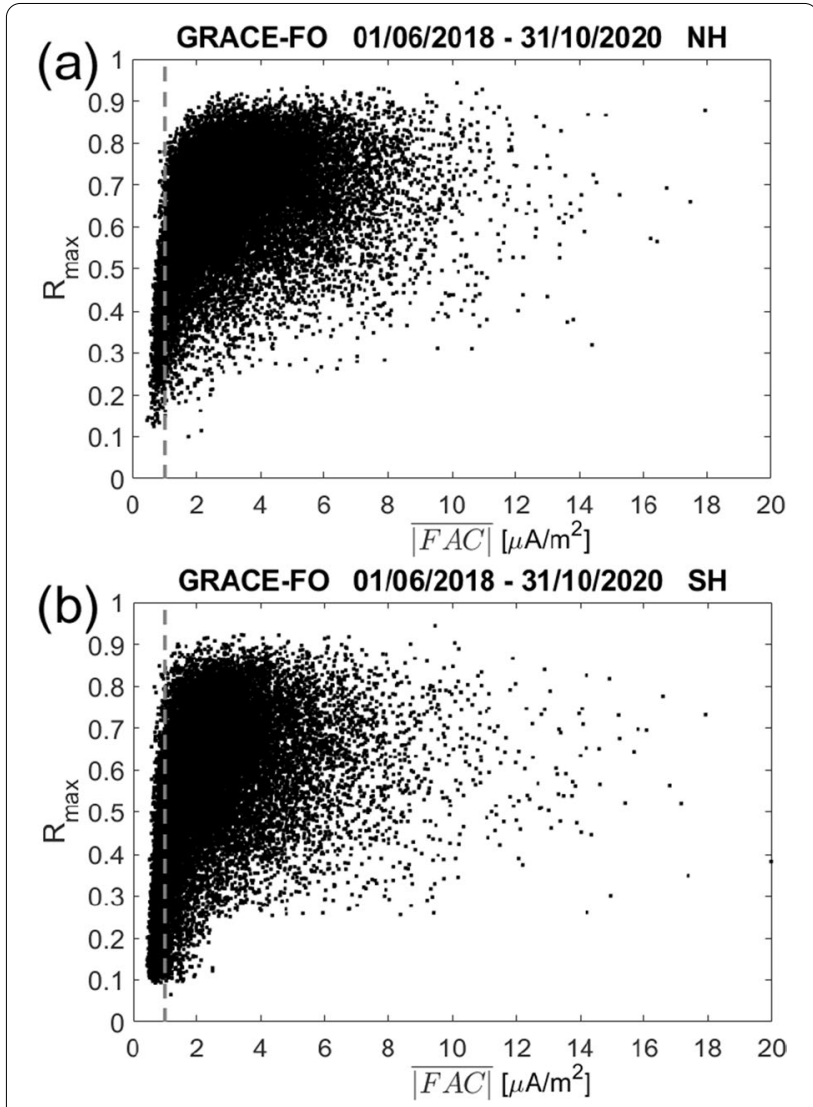

Fig. 4 Distribution of $R_{\max }$ on $\overline{|\mathrm{FAC}|}$. The vertical dashed lines represent the applied threshold of $1 \mu \mathrm{A} / \mathrm{m}^{2}$ 


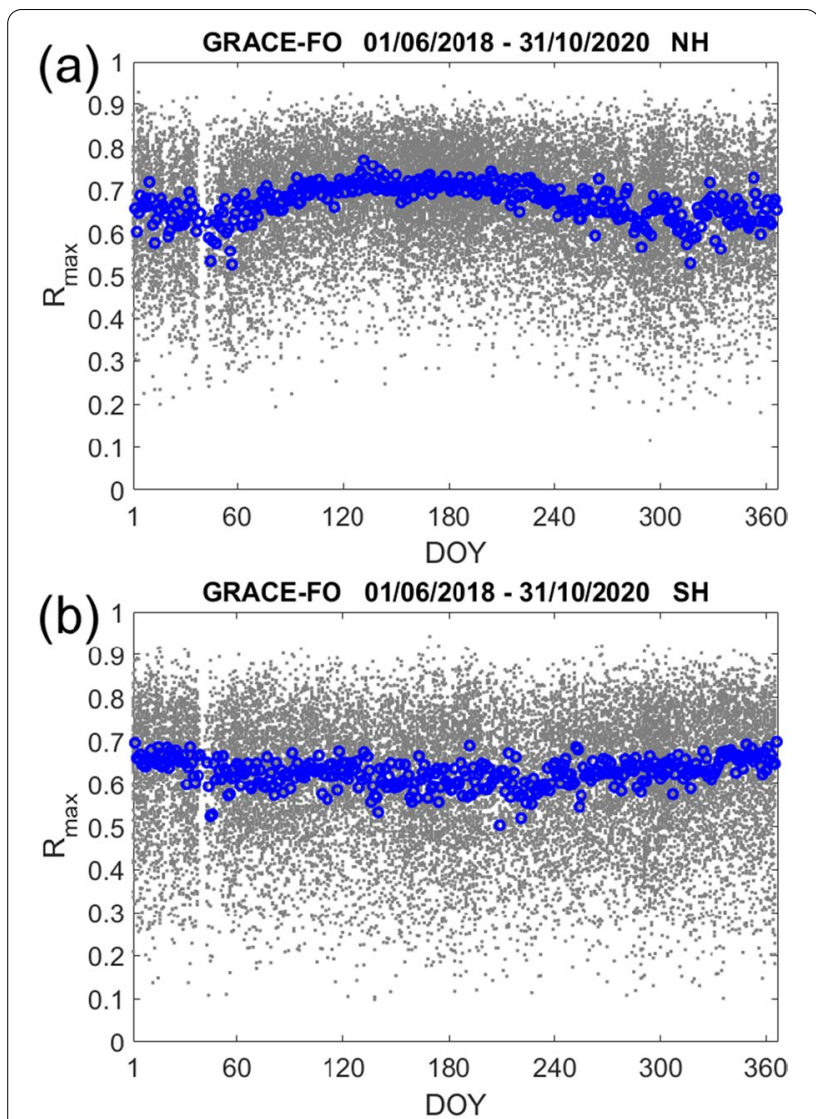

Fig. 5 Seasonal dependence of the $R_{\text {max }}$. The grey dots represent the correlation derived from each high-latitude orbital crossing, and the blue circles represent the median values in each DOY bin

other words, the $R_{\max }$ is larger during local summer for both hemispheres.

Figure 6 further presents the MLT distribution of $R_{\max }$ in the two hemispheres, and the median values of $R_{\max }$ in each MLT bin (width of $1 \mathrm{~h}$ ) are shown similarly as blue circles. A clear feature seen here is that $R_{\max }$ show larger values around dawn and dusk hours, slightly lower values around midnight, and the lowest value is found around noon. This feature applies to both hemispheres. For a more specified impression of the small-scale FAC structures at different MLT, Fig. 7 presents four individual examples of FACs profiles of GF1 and GF2 for noon, midnight, dusk and dawn hours. The correlations at noon and midnight are low, thus small-scale FAC variations, shorter than spacecraft separation distance, are important. The correlations at dawn and dusk are higher, thus FACs appear persistent at scale lengths larger than the spacecraft separation distance.

Figure 8 shows the dependence of $R_{\max }$ over magnetic activity, separately for different MLT sectors. Here we used the solar wind merging electric field, $E_{m}$, to

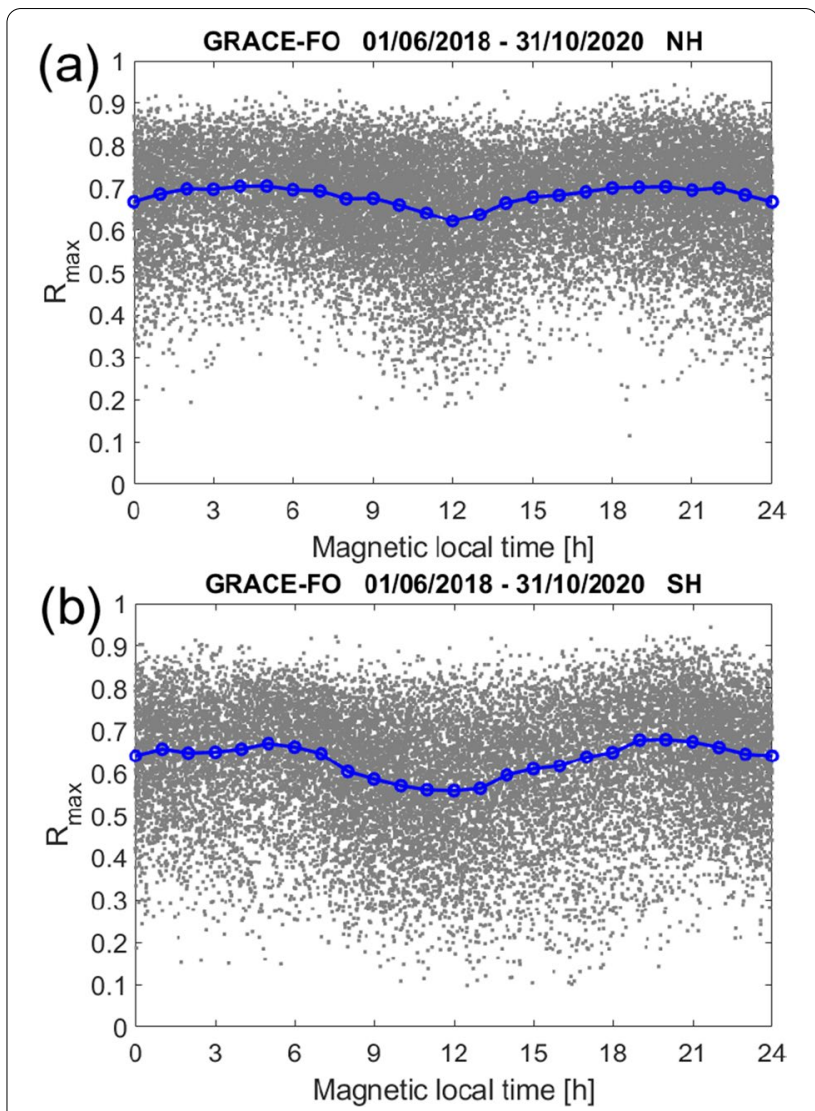

Fig. 6 Similar to Fig. 5, but for the distribution of $R_{\max }$ on $M L T$

represent the magnetic activity. Xiong et al. (2014) found that the location of the auroral oval equatorward boundary shows nearly linear dependence on the intensity of $E_{m}$, being an expression of geomagnetic activity. For more details about how to derive $E_{m}$ from the solar wind and IMF parameters, the readers are referred to Newell et al. (2007) and Xiong et al. (2014). Less events of low $R_{\max }$ appear for larger $E_{m}$; however, the median values (blue circles) do not show prominent dependence on $E_{m}$, and this feature applies for both hemispheres (the results for the southern hemisphere are not shown). This result suggests that the small-scale FAC structures do not strongly depend on magnetic activity.

The last question we want to address is the persistence of FAC structures depending on their scale lengths. Figure 9 (top) presents one example of the original FACs data at $1-\mathrm{Hz}$ resolution, and the panels below reflect low-pass filtered time series at different cutoff periods for the same event. The original $1-\mathrm{Hz}$ data show rather strong FACs reaching current densities beyond $9 \mu \mathrm{A} / \mathrm{m}^{2}$, and the smallest scale-size being resolved is about $15 \mathrm{~km}$ (considering the Nyquist sampling theorem and the spacecraft velocity of $7.5 \mathrm{~km} / \mathrm{s}$ ). 

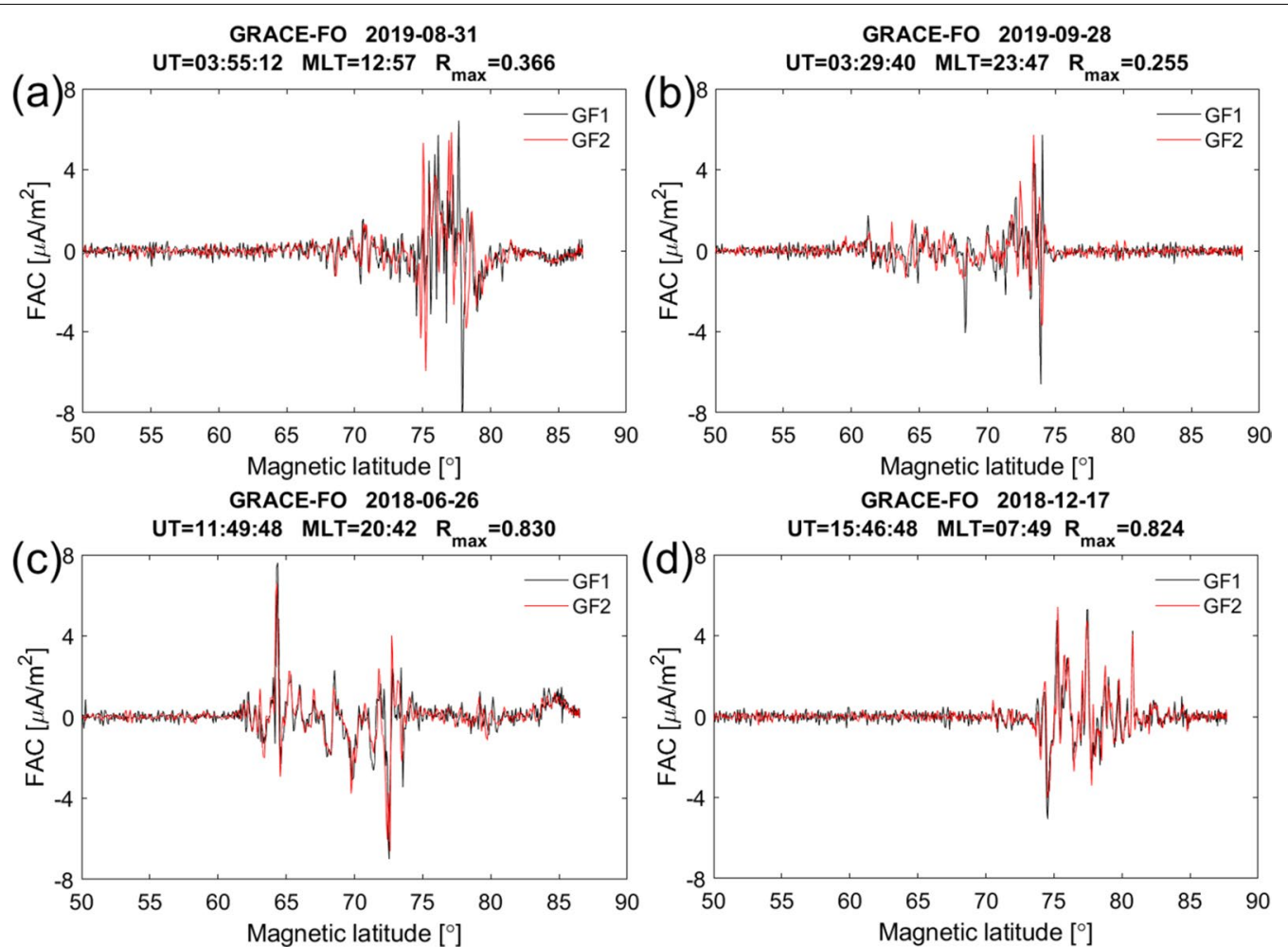

Fig. 7 Four individual examples of the FACs profiles from GF1 and GF2, representing the situations around a noon, $\mathbf{b}$ midnight, $\mathbf{c}$ dusk and $\mathbf{d}$ dawn hours

Here, $R_{\max }$ is 0.42 . The amplitudes decrease for increasing scale lengths and their correlation between the two spacecraft increases. After applying a filter with cutoff periods of $10 \mathrm{~s}$, corresponding to scale-lengths larger than $75 \mathrm{~km}$, FACs seem persistent with a correlation of $R_{\max }=0.96$. At such scale-length, FACs start to reflect the basic R1/R2 pattern as reported by Iijima and Potemra (1976a).

The example shown in Fig. 9 represents the midnight case. To get a more quantitative picture of the temporal variability of small-scale FAC structures at different MLT hours, Fig. 10 shows the distribution of $R_{\max }$ as a function of MLT and filter lengths, separately for three different seasons and two hemispheres. The three seasons are defined as: December solstice (November to February), equinoxes (March, April, September, October), and June solstice (May to August). For each subpanel, the first vertical column represents correlation results from the original $1-\mathrm{Hz}$ FACs time series, and all the other values are from low-pass filtered data with cutoff periods as listed in the abscissae. The original $1-\mathrm{Hz}$ recordings show correlations below 0.6 at noon and slightly higher values (about 0.75) are observed at dawn and dusk. After applying filters with cutoff period larger than $10 \mathrm{~s}$, correlations are significantly improved $\left(R_{\max }>0.9\right)$ at all local times, implying small-scale FAC structures have been smoothed out.

The correlations between two spacecraft are generally higher in the northern hemisphere than that in the southern hemisphere, which can also be seen from Figs. 5 and 6 . For the seasonal difference, an interesting feature shown in Fig. 10 is that the correlations during local summer are higher than that during local winter, most prominent for the noon hours.

\section{Discussion}

In this study we provide a detailed survey on the scalesize of auroral FACs. Though it is possible, by applying filters to the FACs time series from single satellite measurements, to separate the structures of different scale sizes, temporal and spatial variations cannot be distinguished in this way. In addition, the obtained structures are interpreted as FAC spatial variations along the satellite orbit. The GRACE-FO mission, with one spacecraft following the other on the same orbit, provides a good opportunity to derive observations at the same position but at two different times (about $25 \mathrm{~s}$ separated), thus the temporal variations of the magnetic field, which is misinterpreted as FAC, especially for small-scale ones, can be determined. We want to note that the GRACE-FO 

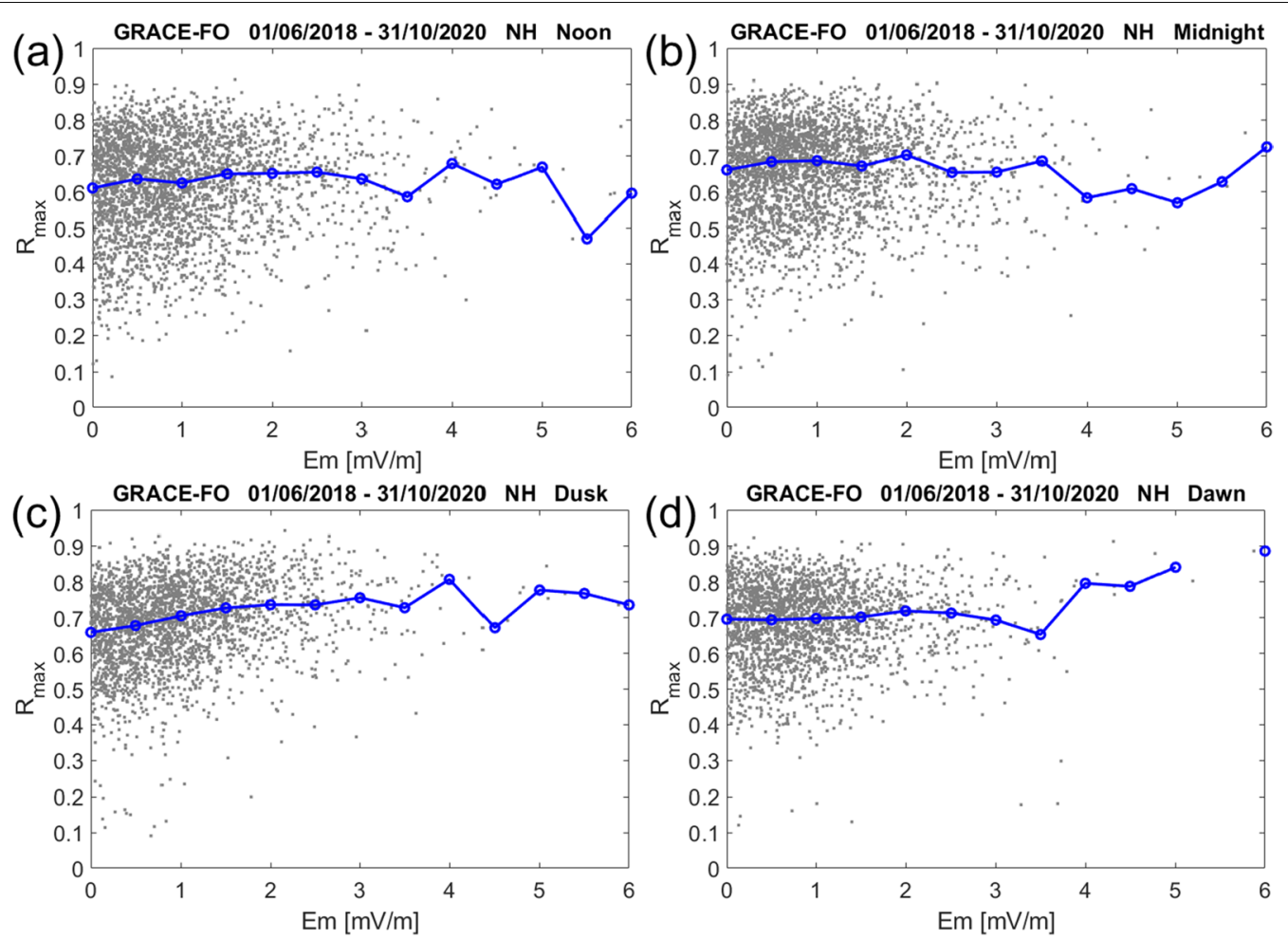

Fig. 8 Distribution of $R_{\max }$ on magnetic activity (represented by the solar wind merging electric field, $E_{m}$ ), separately for different MLT sectors. Here we only present the results in the northern hemisphere, as it is similar in the southern hemisphere

1- $\mathrm{Hz}$ FAC data resolve structures as fine as about $15 \mathrm{~km}$, and as shown in Figs. 9 and 10, the correlations between FACs from GF1 and GF2 improve significantly only when applying filter with cutoff period of $10 \mathrm{~s}$ or longer. This result implies that for "small-scale" FACs with horizontal scale lengths between 15 and $150 \mathrm{~km}$ the assumption of stationary, required for single-satellite FAC estimates (e.g., Lühr et al. 2014), is violated. To avoid such complications, the dual-spacecraft Swarm Level-2 FAC product applies a low-pass filter of $20 \mathrm{~s}$ cutoff period to the magnetic field data before FAC estimates (Ritter et al. 2013).

In general, the results confirm previous findings that the small-scale FACs, are dominated by the kinetic Alfvén waves and are quite dynamic. Conversely, the large-scale FACs can be considered as quasi-static and persisting longer than 1 min (Gjerloev et al. 2011; Lühr et al. 2014). A prominent feature is that the correlations of FACs between GF1 and GF2 is highest around dusk and early night, a little less around dawn hours, and even lower around midnight and lowest around noon. This typical MLT dependence suggests that compared to the dusk and dawn hours, the small-scale FACs appear more frequently at noon and midnight, where they are related to the cusp and substorm activities, respectively (Neubert and Christiansen 2003). Though Lühr et al. (2014) found that the size-dependent variability at noon is comparable to the midnight hours, much longer data set shows that the correlations are slightly lower at noon hours. This result supports the findings by Gjerloev et al. (2011) that differences exist in FAC characteristics on the dayside and on the nightside, in terms of dynamics of the current systems.

A similar MLT dependence of the small-scale FACs was presented by Neubert and Christiansen (2003). They reported that small-scale FAC densities reaching 1000 $\mu \mathrm{A} / \mathrm{m}^{2}$ are distributed throughout the auroral oval, but were most intense in the cusp and pre-noon cusp regions (see their Fig. 5). They further explained that such intense small-scale FACs are the result of magnetic reconnection processes connected to the cusp. However, Neubert and Christiansen (2003) only considered the intensity of small-scale FACs, while the correlation parameter, $R_{\max }$, used in this study depends on both intensity and scale size. A more instructive comparison is the result presented in Fig. 8 (right panel) of Rother et al. (2007), that shows the occurrence rate of small-scale FACs. There, most small-scale events were observed in the cusp around noon, and a second peak of occurrence at midnight hours. As a result, two minima of occurrence were observed around 0500 and 1900 MLT, which correspond 


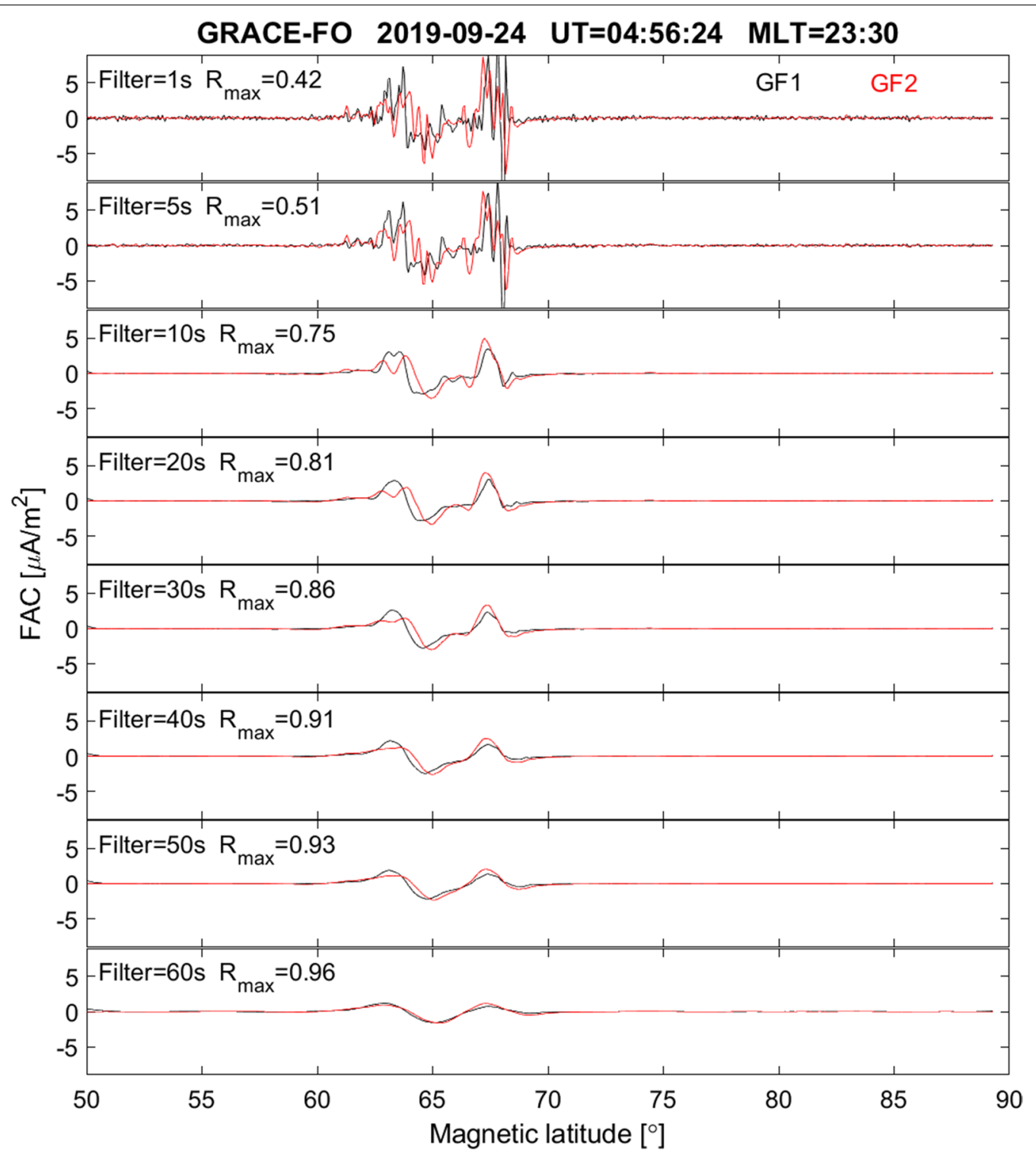

Fig. 9 One example of (top) the original FACs data at 1- $\mathrm{Hz}$ resolution, and (rest panels) the low-pass filtered time series at different cutoff periods

well with better correlations around these two local time sectors in the GRACE-FO data (Fig. 6). We want to note that the "small-scale" structures resolved by Neubert and Christiansen (2003) as well as Rother et al. (2007) were both at sub-kilometer scale, while the "small-scale" structures resolved by GRAC-FO in this study are at some tens of kilometers. This implies that the kinetic Alfvén waves dominated the FACs from sub-kilometer to some tens of kilometers. Although Ishii et al. (1992) showed that a cutoff exists for the kinetic Alfvén waves at periods between 4 and $10 \mathrm{~s}$ depending on the ionospheric conductivity, and Lühr et al. (2014) found that the small-scale FACs have a typical persistent period of less than $10 \mathrm{~s}$, the examples shown in Fig. 7 reveal that the small-scale FAC structures at the same location sometimes can persist for more than $25 \mathrm{~s}$, especially in the dawn or dusk sectors.

The seasonal dependence of correlations appears unexpected compared to earlier findings. Rother et al. (2007) found that small-scale FACs with high amplitude appear more frequently in local summer and light condition. Neubert and Christiansen (2003) also found that the amplitude of small-scale FACs is much larger in light condition. Figure 5 shows slightly higher $R_{\max }$ during local summer and the seasonal dependence of $R_{\max }$ is dominated by low correlations of small-scale FACs around noon hours (Fig. 10). We note, that the $R_{\max }$ of the 

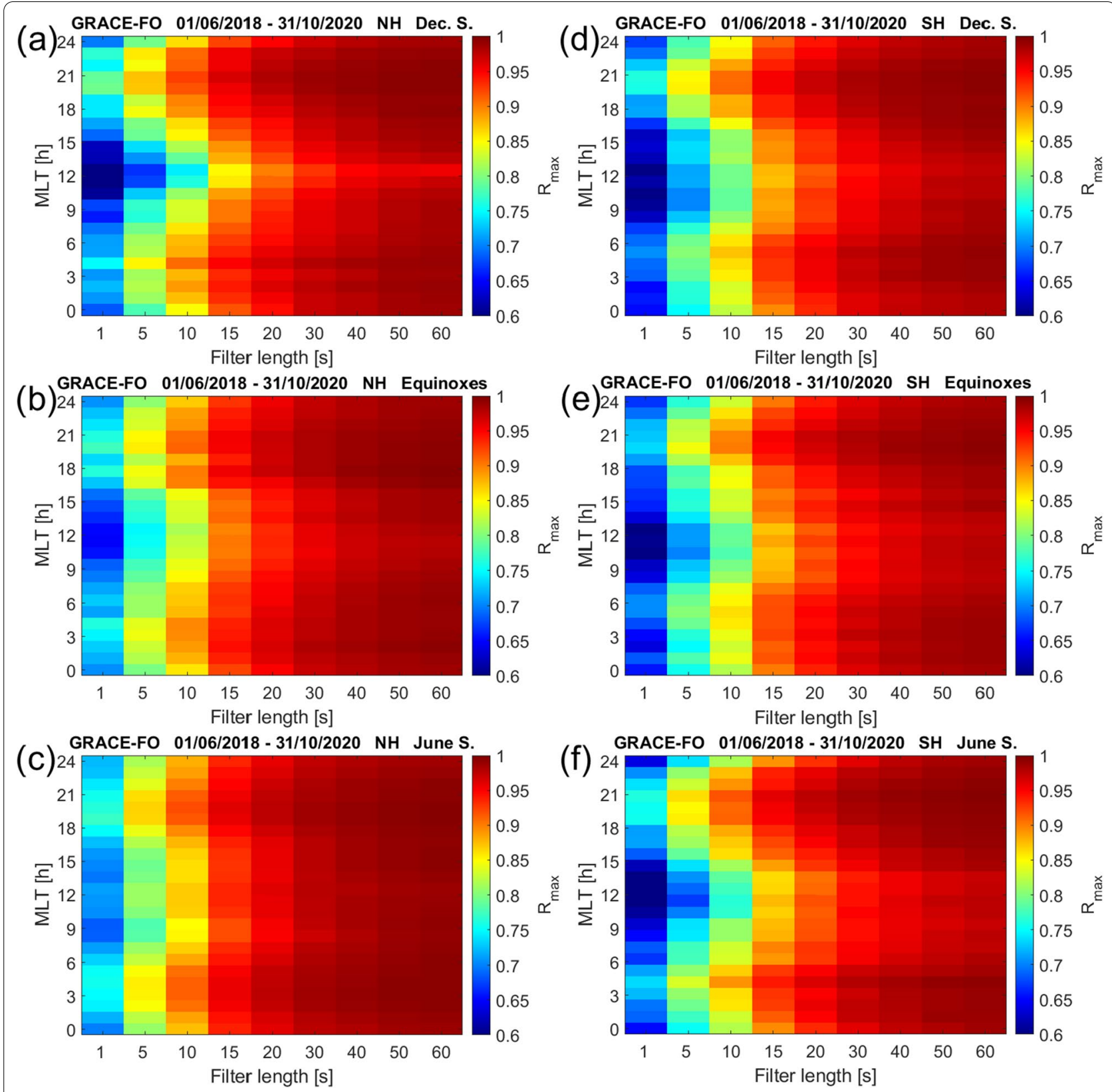

Fig. 10 Distribution of $R_{\max }$ as a function of MLT and filter lengths, separately for three seasons and two hemispheres

cross-correlation analysis is not separated by the intensity of FACs. It is known that the highly variable smallscale currents have larger amplitudes, and as shown in Fig. 4, for larger $\overline{|F A C|}$, there are much less events that show low $R_{\max }$ implying the current intensity somehow plays a role in affecting the correlations between GRACE-FO two satellites. Rother et al. (2007) also found that the small-scale FACs are generally accompanying large-scale FAC sheet, and the larger scale FACs have larger intensity during local summer (see also Laundal et al. 2017). From this point of view, the larger amplitude of small-scale FACs seem to balance the influence of the greater number of small-scale FACs events appearing in local summer on the resulted $R_{\max }$. To further investigate this assumption, we performed a test on the small-scale FACs. For each high-latitude orbital crossing, we first applied a high-pass filter with $20 \mathrm{~s}$ cutoff period to the original $1-\mathrm{Hz}$ FAC data series to isolate the small-scale FACs. Then low-pass filters with different cutoff periods $(5,10,15, \ldots, 60 \mathrm{~s})$ are applied to the small-scale FACs. 
The root-mean-square (RMS), which is a measure of the fluctuation amplitude of FACs around its mean value and thus relates to the intensity of small-scale FACs, is calculated for each $60 \mathrm{~s}$ piece of FAC data series. Finally, the maximum RMS of each orbital crossing is recorded. Figure 11 shows the median values of maximum RMS for different local time and hemispheres, and the data have been divided into three seasons. Here, the RMS of small-scale FACs have largest value at noon during local summer, which agrees well with the largest small-scale FACs intensity at cusp during local summer as reported by Rother et al. (2007) as well Neubert and Christiansen (2003). Figure 11 shows an RMS reduced by an order of magnitude for filter lengths above $20 \mathrm{~s}$, because the variations of small-scale FACs with periods above $20 \mathrm{~s}$ have been suppressed by the filters. This result also reveals that the intensity of FACs needs to be taken into account when interpreting the $R_{\max }$ of cross-correlation analysis.
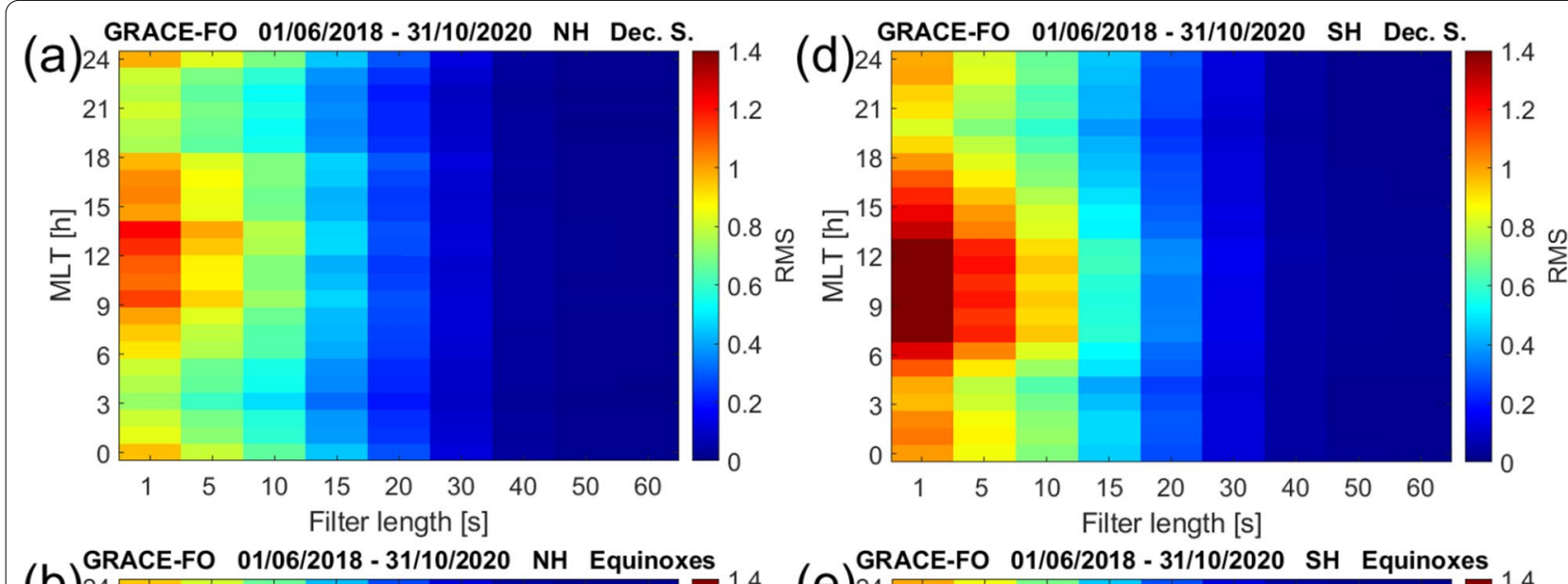

(b)

01/06/2018-31/10/2020 NH Equinoxes

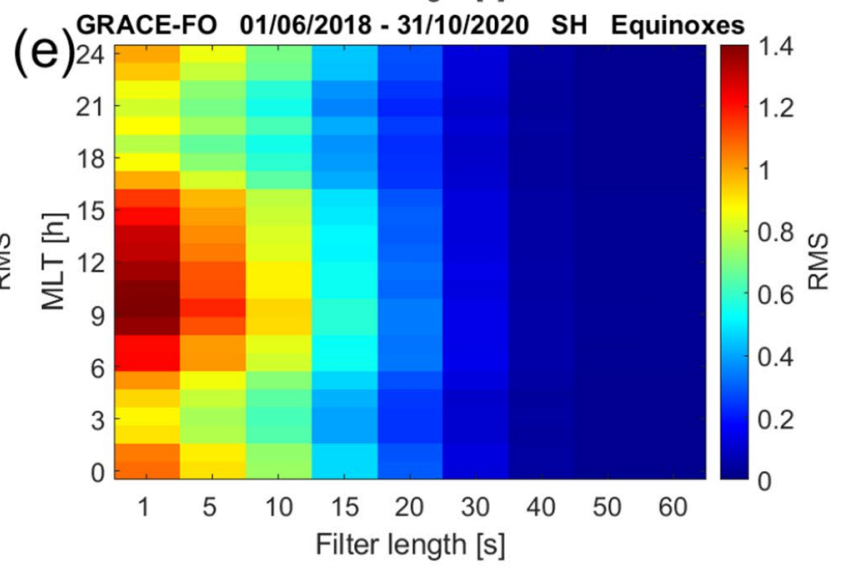

\section{(C) GACE-FO 01/06/2018-31/10/2020 NH June S.}
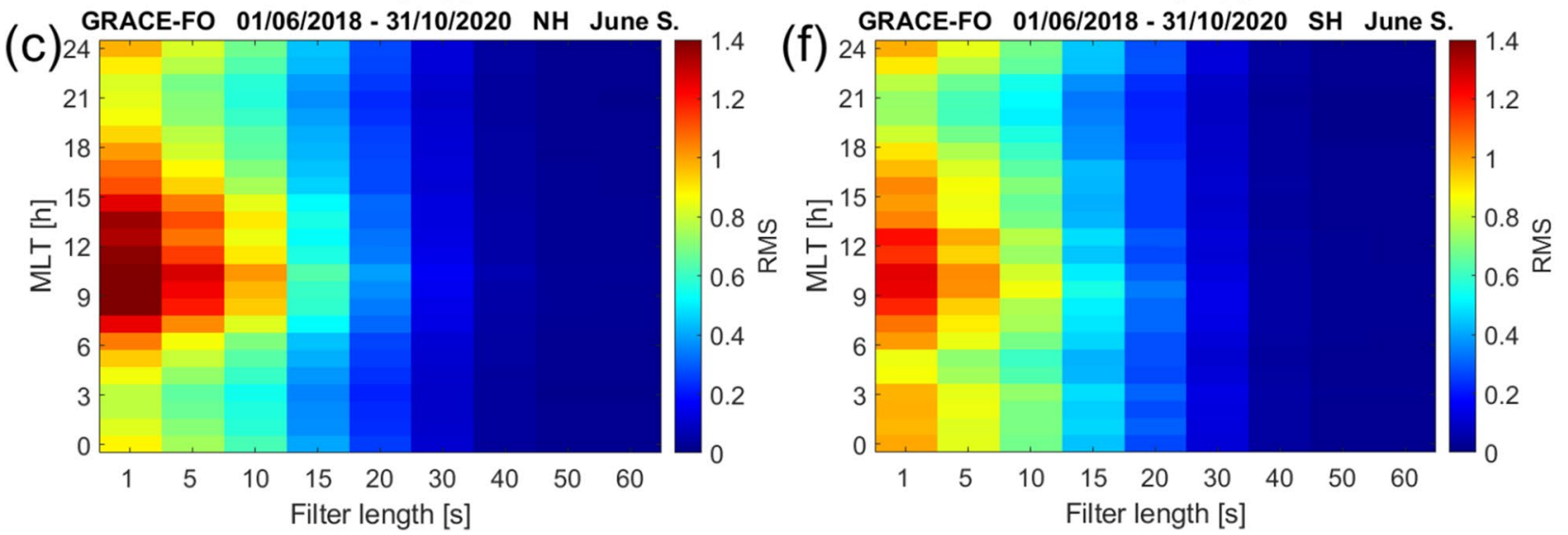

Fig. 11 Similar as Fig. 10, but for the RMS of small-scale FACs 
Variation characteristics of the small-scale magnetic activity are more complicated. Rother et al. (2007) showed that the intensity of small-scale FACs increase with large $K p$ index, and the location of small-scale FACs extends to higher/lower latitude around noon/midnight hours, due to the expansion of the auroral oval. In addition, Neubert and Christiansen (2003) mentioned an enhanced occurrence rate of small-scale FACs on the nightside under magnetically active periods. However, such a dependence on magnetic activity cannot be recognized in the GRACE-FO results. Neither the value of $R_{\max }$ reduces nor more events with lower $R_{\max }$ are seen during more active periods for the midnight hours. We speculate that no prominent magnetic dependence is found for the small-scale FACs analysis, because the considered data period from June 2018 to October 2020 coincides with the solar minimum, which does not contain many events of high magnetic activity. Further studies are needed, covering both solar maximum and minimum, for addressing the magnetic activity dependence of small-scale FACs.

\section{Summary}

Using the well-calibrated magnetic data from the nondedicated magnetic field mission of GRACE-FO, we performed a statistical analysis of the small-scale FACs at auroral latitudes. The main findings are summarized as below:

1. Auroral FACs derived from GRACE-FO are consistent with the results derived from previous magnetic missions. Small-scale FACs of horizontal sizes on the order of tens of kilometers, dominated by the kinetic Alfvén waves, vary significantly within $25 \mathrm{~s}$ when observed at the same location, while the large-scale FACs $(>150 \mathrm{~km})$ can be considered as quasi-static and are persistent for longer than $1 \mathrm{~min}$.

2. With two spacecraft following each other on the same orbit, the GRACE-FO reveals that the FACs structures with scale sizes of some tens of kilometers sometimes persistent longer than 25 s, e.g., around dusk and dawn, which is longer than the typical persistent period (10 s) of kinetic Alfvén waves as earlier reported. This result also means that short scale lengths are less frequent during dusk and dawn.

3. The FACs show relatively better correlations at dusk and dawn hours, while lower correlations around midnight and lowest correlations around noon, implying that the small-scale FACs most frequently appear at the noon cusp and midnight substorm regions.

4. Slightly better correlations of FACs between two spacecraft are found during local summer, and such seasonal dependence is dominated by the correlations of small-scale FACs at noon. However, the small-scale FACs at noon also have largest occurrence and intensity during local summer, which reveals that when interpreting the cross-correlation analysis of FACs the intensity of FACs needs to be taken into account.

\begin{abstract}
Abbreviations
CHAMP: CHAllenging Minisatellite Payload; FACs: Field-aligned currents; GRACEFO: Gravity Recovery and Climate Experiment Follow-On; GF1: GRACE FollowOn 1; GF2: GRACE Follow-On 2; IMF: Interplanetary magnetic field; LT: Local time; MLT: Magnetic local time; MLAT: Magnetic latitude; NBZ: Northward IMF Bz; NEC: North-east-center; DOY: Day of year.
\end{abstract}

\section{Acknowledgements}

The GRACE-FO is operated under a partnership between NASA and the Helmholtz Centre Potsdam, GFZ German Research Centre for Geosciences. We thank the teams at NASA and GFZ for processing and providing the magnetic data of GRACE-FO mission.

\section{Authors' contributions}

CX analyzed the FACs data and wrote the manuscript. IM pre-processed and calibrated the magnetic data, and JR derived the FACs data. CX and CS interpreted the results. $\mathrm{HL}, \mathrm{YZ}, \mathrm{HW}$, and GK helped for the discussions. All authors read and approved the final manuscript.

\section{Funding}

CX is supported by the National Natural Science Foundation of China (42174191) and the start-up program of Wuhan University (600460020). YZ is supported by the National Natural Science Foundation of China (42174186). This work is also supported by the ISSI-BJ project "the electromagnetic data validation and scientific application research based on CSES satellite" and ISSI/ISSI-BJ project "Multi-Scale Magnetosphere-Ionosphere-Thermosphere Interaction".

\section{Availability of data and materials}

The data generated and analyzed in this paper are available at ftp://isdcftp. gfzpotsdam.de/grace-fo/MAGNE TIC_FIELD (Michaelis et al. 2021). The solar wind and IMF data are available at OMNIWeb database https://omniweb.gsfc. nasa.gov/form/omni_min.html.

\section{Declarations}

\section{Competing interests}

The authors declare that they have no competing interests.

\section{Author details}

${ }^{1}$ Department of Space Physics, Electronic Information School, Wuhan University, Wuhan 430072, China. ${ }^{2}$ Leibniz Institute of Atmospheric Physics at the University of Rostock, Schlossstr. 6, 18225 Kühlungsborn, Germany. ${ }^{3}$ GFZ German Research Centre for Geosciences, Section 2.3, Geomagnetism, Telegrafenberg, 14473 Potsdam, Germany.

Received: 7 September 2021 Accepted: 3 November 2021

Published online: 15 November 2021

\section{References}

Anderson BJ, Korth H, Waters CL, Green DL, Stauning P (2008) Statistical Birkeland current distributions from magnetic field observations by the Iridium constellation. Ann Geophys 26:671-687. https://doi.org/10.5194/ angeo-26-671-2008

Benkevich L, Lyatsky W, Cogger LL (2000) Field-aligned currents between conjugate hemispheres. J Geophys Res 105(A12):27727-27737. https:// doi.org/10.1029/2000JA900095 
Birkeland K (1908) The Norwegian aurora polaris expedition 1902-1903, vol 1. H. Aschelhoug \& Co, Christiania, Norway

Birkeland K (1913) The Norwegian aurora polaris expedition 1902-1903, vol 2. H. Aschelhoug \& Co, Christiania, Norway

Cnossen I, Wiltberger M, Ouellette JE (2012b) The effects of seasonal and diurnal variations in the Earth's magnetic dipole orientation on solar windmagnetosphere-ionosphere coupling. J Geophys Res 117:A11211. https:// doi.org/10.1029/2012JA017825

Emmert JT, Richmond AD, Drob DP (2010) A computationally compact representation of Magnetic-Apex and Quasi-Dipole coordinates with smooth base vectors. J Geophys Res 115:A08322. https://doi.org/10.1029/2010J A015326

Finlay CC, Kloss C, Olsen N, Hammer MD, Tøffner-Clausen L, Grayver A, Kuvshinov A (2020) The CHAOS-7 geomagnetic field model and observed changes in the South Atlantic anomaly. Earth Planets Space. https://doi. org/10.1186/s40623-020-01252-9

Ganushkina NY, Liemohn MW, Dubyagin S, Daglis IA, Dandouras I, De Zeeuw DL, Ebihara Y, Ilie R, Katus R, Kubyshkina M, Milan SE, Ohtani S, Ostgaard N, Reistad JP, Tenfjord P, Toffoletto F, Zaharia S, Amariutei O (2015) Defining and resolving current systems in geospace. Ann Geophys 33:1369-1402. https://doi.org/10.5194/angeo-33-1369-2015

Gjerloev JW, Ohtani S, lijima T et al (2011) Characteristics of the terrestrial fieldaligned current system. Ann Geophys 29:1713-1729. https://doi.org/10. 5194/angeo-29-1713-2011

lijima T, Potemra TA (1976a) The amplitude distribution of field-aligned currents at northern high latitudes observed by TRIAD. J Geophys Res 81:21652174. https://doi.org/10.1029/JA081i013p02165

lijima T, Potemra TA (1976b) Field-aligned currents in the dayside cusp observed by TRIAD. J Geophys Res 81:5971-5979. https://doi.org/10.1029/JA081 i034p05971

lijima T, Potemra TA, Zanetti LJ, Bythrow PF (1984) Large-scale Birkeland currents in the dayside polar region during strongly northward IMF: a new Birkeland current system. J Geophys Res 89:7441-7452. https://doi.org/10. 1029/JA089iA09p07441

Ishii M, Sugiura M, lyemori T, Slavin JA (1992) Correlation between magnetic and electric fields in the field-aligned current regions deduced from DE-2 observations, J. Geophys. Res 97, 13, 877-13, 887. Doi: https://doi.org/10. 1029/92JA00110.

Landerer FW, Flechtner FM, Save H et al (2020) Extending the global mass change data record: GRACE follow-on instrument and science data performance. Geophys Res Lett 47(12):e2020GL088306. https://doi.org/10. 1029/2020GL088306

Laundal KM, Cnossen I, Milan SE, Haaland SE, Coxon J, Pedatella NM et al (2017) North-south asymmetries in Earth's magnetic field. Space Sci Rev 206(1-4):225-257. https://doi.org/10.1007/s11214-016-0273-0

Lühr H, Warnecke J, Zanetti LJ, Lindqvist PA, Hughes TJ (1994) Fine structure of field-aligned current sheets deduced from spacecraft and ground-based observations: Initial FREJA results. Geophys Res Lett 21:1883-1886. https:// doi.org/10.1029/94GL01278

Lühr H, Warnecke J, Rother M (1996) An algorithm for estimating field-aligned currents from single spacecraft magnetic field measurements: a diagnostic tool applied to Freja satellite data. Geosci Remote Sens 34:1369-1376. https://doi.org/10.1109/36.544560

Lühr H, Rother M, Kohler W et al (2004) Thermospheric up-welling in the cusp region, evidence from CHAMP observations. Geophys Res Lett 31:L06805. https://doi.org/10.1002/2014GL062453

Lühr H, Park J, Gjerloev JW et al (2014) Field-aligned currents'scale analysis performed with the Swarm constellation. Geophys Res Lett 42:1-8. https:// doi.org/10.1002/2014GL062453

Michaelis, I., Stolle, C., Rother, M. (2021), GRACE-FO calibrated and characterized magnetometer data. https://doi.org/10.5880/GFZ.2.3.2021.002

Milan SE, Evans TA, Hubert B (2010) Average auroral configuration parameterized by geomagnetic activity and solar wind conditions. Ann Geophys 28:1003-1012. https://doi.org/10.5194/angeo-28-1003-2010

Milan SE, Clausen LBN, Coxon JC, Carter JA, Walach M-T, Laundal K et al (2017) Overview of solar wind-magnetosphere-ionosphere-atmosphere coupling and the generation of magnetospheric currents. Space Sci Rev 206(1):547-573. https://doi.org/10.1007/s11214-017-0333-0
Mobley F, Eckard L, Fountain G et al (1980) MAGSAT-A new satellite to survey the earth's magnetic field. IEEE Trans Magn 16(5):758-760. https://doi.org/ 10.1109/TMAG.1980.1060781

Neubert T, Christiansen F (2003) Small-scale, field-aligned currents at the topside ionosphere. Geophys Res Lett 30(19):2010. https://doi.org/10.1029/ 2003GL017808

Newell PT, Sotirelis T, Liou K, Meng C-I, Rich FJ (2007) A nearly universal solar wind-magnetosphere coupling function inferred from 10 magnetospheric state variables. J Geophys Res 112:A01206. https://doi.org/10.1029/2006J A012015

Primdahl F, Bahnsen A, Ejiri M et al (1984) Rocket borne and groundbased observations of coincident field-aligned currents, electron beams, and plasma density enhancements in the afternoon auroral oval. Planet Space Sci 32(5):561-583. https://doi.org/10.1016/0032-0633(84)90107-7

Ritter P, Lühr H, Rauberg J (2013) Determining field-aligned currents with the Swarm constellation mission. Earth Planets Space 65:1285-1294. https:// doi.org/10.5047/eps.2013.09.006

Rother M, Schlegel K, Lühr H (2007) CHAMP observation of intense kilometerscale field-aligned currents, evidence for an ionospheric Alfvén resonator. Ann Geophys 25:1603-1615. https://doi.org/10.5194/angeo-25-1603-2007

Shi JK, Cheng ZW, Zhang TL et al (2010) South-north asymmetry of fieldaligned currents in the magnetotail observed by Cluster. J Geophys Res 115:A07228. https://doi.org/10.1029/2009JA014446

Shi Y, Knipp DJ, Matsuo T, Kilcommons L, Anderson B (2020) Modes of FACs variability and their hemispheric asymmetry revealed by inverse and assimilative analysis of iridium magnetometer data. J Geophys Res Space Phys 125:e2019JA027265. https://doi.org/10.1029/2019JA027265

Stolle C, Michaelis I, Xiong C et al (2021) Observing Earth's magnetic environment with the GRACE-FO mission. Earth Planets Space 73:51. https://doi. org/10.1186/s40623-021-01364-w

Tapley BD, Bettadpur S, Watkins M, Reigber C (2004) The gravity recovery and climate experiment: mission overview and early results. Geophys Res Lett 31:L09607. https://doi.org/10.1029/2004GL019920

Trenchi L, Kauristie K, Käki S et al (2019) ESA field-aligned currents methodology inter-comparison exercise. In: Dunlop M, Lühr H (eds) lonospheric multi-spacecraft analysis tools, ISSI Scientific Reports Series 17. Springer International Publishing. https://doi.org/10.1007/978-3-030-26732-2

Wang H, Lühr H, Ma SY (2005) Solar zenith angle and merging electric field control of field-aligned currents: a statistical study of the Southern Hemisphere. J Geophys Res 110:A03306. https://doi.org/10.1029/2004JA010530

Workayehu AB, Vanhamäki H, Aikio AT (2020) Seasonal effect on hemispheric asymmetry in ionospheric horizontal and field-aligned currents. J Geophys Res Space Phys 125:e2020JA028051. https://doi.org/10.1029/2020JA0280 51

Xiong C, Park J, Lühr H, Stolle C, Ma SY (2010) Comparing plasma bubble occurrence rates at CHAMP and GRACE altitudes during high and low solar activity. Ann Geophys 28:1647-1658. https://doi.org/10.5194/ angeo-28-1647-2010

Xiong C, Lühr H, Wang H et al (2014) Determining the boundaries of the auroral oval from CHAMP field-aligned current signatures-Part 1. Ann Geophys 32:609-622. https://doi.org/10.5194/angeo-32-609-2014

Xiong C, Stolle C, Alken P, Rauberg J (2020) Relationship between large-scale ionospheric field-aligned currents and electron/ion precipitations: DMSP observations. Earth Planets Space 72:147. https://doi.org/10.1186/ s40623-020-01286-z

Zhou Y-L, Lühr H (2017) Net ionospheric currents closing field-aligned currents in the auroral region: CHAMP results. J Geophys Res Space Physics 122:4436-4449. https://doi.org/10.1002/2016JA023090

Zmuda AJ, Martin JH, Heuring FT (1966) Transverse magnetic disturbances at 1100 kilometers in the auroral region. J Geophys Res 71:5033-5045. https://doi.org/10.1029/JZ071i021p05033

\section{Publisher's Note}

Springer Nature remains neutral with regard to jurisdictional claims in published maps and institutional affiliations. 